\title{
Cancer in Population of African Ancestry: A Review
}

\author{
Thomas Smith, Anita Mandal, Roseline Leger, Meshalin Leon and Prabir K. \\ Mandal*
}

Edward Waters College, Biology Program, Jacksonville, FL 32209

Received: 20th June, 2017; Accepted: 29th June, 2017; Published: 14th July, 2017

*Corresponding author: Prabir K. Mandal, Edward Waters College, Biology Program, Jacksonville, FL 32209.Telephone: 904-470-8091, Fax: 904-4708047; E-mail: prabir.mandal0807@ewc.edu

\begin{abstract}
Objectives: The purpose of this study was to find out the possible causes of the high rates of cancer incidence within the African American community with special reference to the impact of neighborhood socioeconomic deprivation and availability of healthcare resources among underserved minority population.
\end{abstract}

Methods: In order to attain answers to the questions, we have studied thoroughly reviewed the research findings from several scientific sources. Throughout the study, we intended on correlating research from our sources along with observations of our own throughout the African American community of the neighborhood zip codes surrounding Edward Waters College. We would like to govern how the individuals of the community can improve their chances of remaining cancer free after changing necessary lifestyle.

Results: Despite the strides we have made in cancer research over the years, African Americans still suffer the greatest burden for the most common types of cancer. African Americans have the highest death rate amongst any other racial groups and shortest survival time for most cancers of any racial and ethnic group. The causes of these inequalities are complex, and reflect social and economic disparities more than biological differences.

Conclusions: There are multiple factors that can contribute to the reasons why African Americans are prone to cancers. Genetics and biology both be used to help explain why African American breast, ovarian and prostate cancer patients tend to die earlier than patients of other races. We would like to know how economic inequalities can impact the African American community in regards to cancer development. How the factors such as income, education, housing, and overall standard of living play a distinct role in determining the risk factors?

Keywords: African-American; Healthcare; Cancer; Black; Disparity; Prevention; Treatment

\section{Introduction}

Cancer is a group of diseases characterized by uncontrolled growth and spread of abnormal cells. If the spread is not controlled, it can result in death. It is no secret that cancer is very common in the African American community. African Americans have the highest death rate and highest mortality rate of any racial and ethnic group in the US for most cancers. The American Cancer Society reported about 189,910 new cancer cases to be diagnosed among blacks in 2016. The American Cancer Society stated that colorectal cancer death rates remained about $50 \%$ higher in black men than in white men. The American Cancer Society also stated that breast cancer death rates among blacks were $42 \%$ higher than in whites. Why does cancer seem to be so prevalent within the African American community? What can African Americans do to lessen their chances of developing cancer? What can be done to prevent future generations from becoming a statistic? Lastly, is there any prevention that does not include medications? What is it about African Americans that make them so susceptible to cancer?

African Americans have lower 5-year survival rate than whites overall and for each stage of diagnosis for most cancer types. Much of the difference in survival is believed to be due to barriers that limit access to timely, high-quality medical care [1-6]. Furthermore, African Americans are more likely to be diagnosed at a later stage of disease, when treatment choices are more limited and less effective. These issues are recognized to largely reflect socioeconomic disparities associated with race.

\section{Breast cancer}

Breast Cancer is the most commonly diagnosed cancer among African American women. Breast cancers diagnosed in African American women are more likely to have factors associated with poor prognosis, such as higher grade, advanced stage, and negative hormone (estrogen [ER] and progesterone [PR]) receptor status [7-9]. Studies have shown that certain reproductive patterns that are more common among African American women (including giving birth to more than one child, younger age at menarche, early age at first pregnancy), may be associated with increased risk for aggressive subtypes of breast cancer [10]. The most common gene mutations of BRCAl and BRCA2 are associated with the breast cancer. Only 13\% are screened for breast cancer.

\section{Cervical cancer}

Cervical Cancer is almost always caused by persistent genital infection with certain types of human papilloma virus (HPV 16, HPV 18). The incidence rate of cervical cancer is $34 \%$ higher in African American than white women. Cervical cancer is 
one of only two cancers (colorectal is the other) that can actually be prevented through screening with routine Pap tests or through the HPV vaccine. It is estimated that only $9 \%$ of the women, who are eligible for The Centers for Disease Control and Prevention's (CDC) National Breast and Cervical Cancer Early Detection Program (NBCCEDP), are screened for cervical cancer.

\section{Colorectal cancer}

Colorectal cancer (CRC), often referred to as colon cancer, develops in the colon or the rectum. Colon cancer is the third most common cancer in both African American men and women. Major modifiable factors that increase risk for colorectal cancer include obesity, diabetes, and high consumption of red or processed meats, alcohol consumption, and smoking. Studies consistently report that regular physical activity is associated with a lower risk of colon cancer [11]. The majority of CRC can be prevented with proper screening, early detection and removal of adenomatous polyps. The prevalence of a recent screening for colorectal cancer among African Americans has increased to $56 \%$.

\section{Lung cancer}

Lung cancer is the second most common cancer in both African American men and women. Lung cancer is the top cancer killer of women, and some medical experts say that they are seeing more patients in their 20s and 30s, many of them nonsmokers. The disease takes more lives than breast, prostate, colon, and pancreatic cancers combined, and its survival rate is only 16 percent. Besides smoking, exposure to second-hand smoke, asbestos, radon or having a family history can put women at risk. The average incidence rate for cancers of the lung and bronchus during 2005-2009 was 20\% higher in African American men than in white men. The declines in lung cancer death rates are the result of decreases in smoking prevalence over the previous 40 years.

\section{Pancreatic cancer}

Pancreatic cancer is diagnosed in African Americans more often than in other racial/ethnic groups in the United States. When NFL Hall of Famer Gene Upshaw died of pancreatic cancer in 2008, it was the first time many Americans had heard of the disease. Pancreatitis is an inflammatory disease of the pancreas. Pancreatitis may either be acute (sudden and severe) or chronic (long-standing). Individuals that have had repeated attacks of acute pancreatitis can develop chronic pancreatitis [12]. The risk of pancreatic cancer is elevated in all patients with pancreatitis and African Americans are at the highest risk of developing pancreatitis of any racial group. Pancreatic cancer is the fourth leading cause of cancer death in the United States. The incidence is $50-90 \%$ higher in African American than any other racial group in the United States. The environmental and socioeconomic factors are responsible for high incidence of the disease. Cigarette smoking is one of the main causes for the disease. Other risk factors for pancreatic cancer include diabetes mellitus, pancreatitis, and being overweight. Type 2 diabetes (associated with obesity and lack of exercise) doubles the risk of pancreatic cancer. Highly frequent mutational changes affecting the DPC4 gene, pl6 gene, and p53 gene has also been reported. K-ras gene mutations are known to be common in pancreatic cancer [13]. One reason for this lethality is that early pancreatic cancer often causes no symptoms. By the time doctors detect the disease, it has usually spread beyond the pancreas. Once that happens, it is rarely curable. Pancreatic cancer death rates in whites and blacks have gone in opposite directions over the past several decades in the United States. Current treatments for patients with pancreatic cancer include surgery, radiation therapy, chemotherapy, chemoradiation therapy, and targeted therapy.

\section{Prostate cancer}

Prostate cancer is the leading cancer diagnosed in men in the United States. During 2005- 2009, the average annual prostate cancer incidence rate among African American men was $63 \%$ higher than the rate in white men. The only well-established risk factors for prostate cancer are age, race, and family history of the disease. Genetic factor may be associated with the increased risk of prostate cancer amongst African Americans as they have higher incidence of K-ras mutations than Caucasians; and mutated K-ras has been associated with pancreatic cancer, which is a target for therapy. Prostate cancer in African American men is associated with specific changes in the IL-16 gene, according to researchers at the University of Illinois at Chicago College of Medicine [14]. Exposure to heterocyclic amines may increase prostate cancer risk. Human sulfo transferase lAl (SULTIA1) is involved in the bio activation of some dietary pro carcinogens. The COX-2 gene promoter haplotypes may also influence the risk and development of prostate cancer. Elevated expression of PCGEMl, a prostate-specific gene with cell growth-promoting function, is associated with high-risk prostate cancer patients. The germ line mutation of the macrophage scavenger receptor l (MSRl) gene is associated with prostate cancer risk. A genomewide scan of high-risk prostate cancer families in North America has demonstrated linkage of a particular marker to Chromosome I q (HPC1). The digital rectal examination (DRE) and the prostate specific antigen (PSA) are the available diagnosis at present.

\section{Skin cancer}

It occurs when unrepaired DNA damage to skin cells (most often caused by ultraviolet radiation from sunshine or tanning beds) triggers mutations, or genetic defects, that lead the skin cells to multiply rapidly and form malignant tumors. Skin cancer in the form of Basal cell carcinoma (BCC) is the most common cancer in Caucasians, but Squamous Cell Carcinoma (SCC) is the most common skin cancer among African Americans. Despite overall improvements in care across all races over the years, African Americans still suffer the greatest burden for the most common types of cancer. African Americans are more likely to die from melanoma, the deadliest form of skin cancer than are whites. A paper published in the journal Dermato-Endocrinology points the finger at a seemingly obvious but overlooked culprit: the sun. The researchers' theory is that, in northern latitudes, the 
dark skin of African Americans cannot absorb enough sunlight to generate adequate amounts of vitamin $\mathrm{D}$, which is often called the "sunshine vitamin." The body uses ultraviolet rays from the sun to manufacture vitamin D in the inner layers of the skin. Studies have shown that low levels of vitamin D in the blood seem to contribute to a weak immune system and a host of diseases, such as cancer and multiple sclerosis.

\section{Esophageal cancer}

Esophageal cancer is the 8th most common cancer and the 6th most common cause of cancer deaths worldwide. Esophageal adenocarcinoma (EAC) is the most common type in the United States and it begins in mucus secreting glands in the lower portion of the esophagus, while esophageal squamous cell carcinoma (ESCC) is the most prominent type worldwide and most often begins in the middle of the esophagus. Drinking alcohol, smoking or chewing tobacco, being obese, having gastro esophageal reflux disease (GERD) can lead to esophageal cancer.

\section{Discussion}

African Americans might have a higher percentage of cancer rates due to their unhealthy dietary habits. Why do African Americans find it so hard to make the dietary changes necessary for improving their health? Well according to Delores James, individuals feel as if they are abandoning their culture and giving in to the dominant culture. Dr. James's abstract stated, "There was a general perception that 'eating healthfully' meant giving up part of their cultural heritage and trying to conform to the dominant culture. Friends and relatives usually are not supportive of dietary changes. Barriers to eating a healthful diet also included no sense of urgency, the social and cultural symbolism of certain foods, the poor taste of 'healthy' foods, the expense of 'healthy' foods, and lack of information.

Another habit that has to be discontinued is the consumption of fast foods. Fast food refers to the foods that are consumed for convenience. When we are on the go and need a bite to eat, we consume what is quick and cheap. Unfortunately, these commonly are genetically modified foods that contain little to no nutritional value. These fast foods do contain just about everything we do not need. There is no doubt that these dietary habits can have an influence on the risk of cancer development. However, diet does play a pivotal role. Dr. Weisburger stated that "Western dietary traditions involve certain carcinogens and promoters." This is a result of consumption of more fast foods and less fruits and vegetables. Dr. Weisburger had also stated in his abstract how imperative fruits are for lowering risk of cancer. Dr. Weisburger stated, "Importantly, in virtually all situations regular intake of fruits and vegetables appreciably lowers the risk of cancer." The anti-oxidants that are packed in the fruits and vegetables influence our health [15]. Dr. Young Joon stated a few of the many phytochemical benefits of anti-oxidant rich foods. First his study stated that, "Over 2/3 of human cancers could be prevented through lifestyle changes." Dr. Joon's study also stated that, "More than 1,000 different phytochemicals can prevent cancer." Lastly, Dr. Joon's study stated that, "Five servings of fruit and vegetables a day reduce risk of cancer by $50 \%$ !" These statements are evidence to the point that diet and cancer development are very closely related [16].

Based on further research, there is evidence that proves how dietary habits can influence the risk of cancer development. Dr. McVeigh stated, "Today's findings were based on a study of 61,566 people who scientists followed over 12 years. During this time, it was found that $6.8 \%$ of meat eaters $(2,204$ of 32,403$)$, $4.0 \%$ of vegetarians $(829$ of 20,601$)$ and $3.7 \%$ of people who ate fish but no meat $(317$ of 8,562$)$ were diagnosed with cancer." These statistics are proof that if African Americans were more attentive to what they consume, cancer case percentages within the African American community can be divided. The astonishing fact is, this is just a result of altering our diet! Imagine if the numerous of cancer prevention techniques were practiced, a significant changes within the African American community could be observed in regards to cancer development [17].

Substituting meat for leaves can make a difference, but what other alterations could African Americans make to lower the risk of cancer even more? Basically, how the environment of the African Americans differs to that of Caucasians. 97.99\% of African Americans reside in zip code 32209 , and $82.44 \%$ of African Americans reside in 32206. Zip codes 32209 and 32206 also happen to be at the top of the list for poverty percentage in Jacksonville, Florida. Zip code 32206 comes first with a 53.94\% poverty level. How does this correlate to cancer? Well, there are plenty of ways that economical class could influence the health of a population. These two zip codes are Jacksonville's African American community. Most individuals within this community are obviously not well off [18].

With unstable finances, the life and medical insurance are not a priority for these people. Therefore, medical checkups are not as regular as they should be. Without regular medical attention, it is realized one of the main reasons of why cancer and many other diseases are so prevalent in the African American community. The people are unaware of their medical conditions. Without regular checkups or any medical attention, most individuals have a full fledge infection before medical treatment is even considered.

According to Dr. Bruce Waite, "In Duval County there are 29 areas defined as food desert areas. Dr. Waite defines Food dese11s as, "areas or communities that lack physical and/ or economic access to sources of food that comprise a healthy diet. Most measures of food dese11s are based on the distance to a food store, factors that might affect accessibility such as income or vehicle availability, and neighborhood-level factors such as availability of public transpm1ation." These issues are issues that only take place in low-income communities [19]. Considering these areas as food dese11s makes sense. With poor diet being closely correlated with cancer risk, could these food dese11s within zip codes 32209 and 32206 be correlated with malnourishment of those who reside there? Malnourishment could be correlated with the high rate of cancer cases within the African-American community?

Flint is Michigan's poorest city, with $40.1 \%$ of residents living inpove11y. Fifty seven percent of Flint Michigan is African American. It is no question that there is a trend of environmental 
factor throughout African American communities [20]. According to Center for Disease Control, Division of Cancer and Cancer Prevention and Control, incidence and death rates of all cancer among men were highest among African American men. African American women were second most for the incidence rates. However, African American women are first for the death rates. Both African American men and women have high death rates from cancer because of being unaware of the disease before it became lethal and harder to treat. Unawareness is one of the leading causes of cancer development within the African American community. There is not just the one cause that results in unawareness of disease. Financial instability does result in little to no health insurance. Without health insurance, regular health check-up becomes irregular [21].

These people may feel that they are healthy while being infected with a virus. There is no means of detection due to the absence of doctoral examinations and test. Considering that African American communities in Jacksonville the poorest, it is sad to say that many of these individuals are living unaware of any cancer development. Therefore, death rates from all types of cancer are highest among African Americans. By the time the patient is aware of the disease, the disease has already reached its most lethal stages of development. Without enough time to treat the disease, it is obvious that survival chances are slim to none. With poor diet and lack of awareness alone, cancer probability is throughout the roof. The sad fact is, these are not all the causes of cancer prevalence within the African American community.

Exercise is a very big part of weekly routine to maintain health and to relieve stress. Majority of people do not enjoy expending the adenosine-triphosphate to maintain a healthy life style. Lack of exercise can lead to numerous of health issues. Many of us do not take the time out to focus on physical activity. Dr. Friedenreich was interested in how progress in epidemiological research about physical activity and cancer prevention.

Dr. Friedenreich wrote, "The evidence for a causal association between physical activity and colon and breast cancers is found to be "convincing," for prostate cancer to be "probable," for lung and endometrial cancers to be "possible" and for testicular and ovarian cancers to be currently insufficient to make any definitive conclusions" [22]. Although there isn't much support with the several other forms of cancer, a relationship between exercise and cancer development does exist. So how does this relate to the African American community? Dr. August wrote that "Racial/ethnic disparities in exercise and dietary behaviors are most notable among middle-aged, acculturated minorities." The article also read that "Racial/ethnic minorities generally engaged in less healthy exercise and dietary behaviors than whites" [23]. Although these results do not apply to Jacksonville specifically, an analyzation can be drawn based on the percentages. Although exercise and cancer development are not as tightly con-elated as diet, lack of exercise can have .carcinogenic effects. Considering that lack of exercise and poor dietary habits obviously have had a detrimental effect on the African American community, what other factors could play a role?

Dr. Bhardwaj stated, "Prostate cancer incidence and mortality rates are remarkably higher in African-American men as compared to their European-Americans counterparts. Despite these recognitions, precise causes underlying such prevalent racial disparities remain poorly understood. Although socioeconomic factors could account for such differences up to a certain extent, it is now being increasingly realized that such disparity has a molecular basis. Indeed, several differences, including genetic polymorphism, gene mutations, epigenetic modifications, miRNAs alterations, etc., have been reported in malignant prostate tissues from patients of diverse racial backgrounds. Here, we attempt to provide a molecular perspective on prostate cancer racial disparities by gathering available information on these associated factors and discussing their potential significance in disproportionate incidence and clinical outcomes"[24].

So how does genetics affect the risk of cancer development? Dr. Rick Kittles did research on the impact of Genetics associated with Prostate cancer. Dr. Kittles is a biologist specializing in human genetics. According to Dr. Kittle, "These findings highlight ancestry-specific risk variation and implicate prostate-specific in cRNAs at the 8q24 prostate cancer susceptibility region". With the identification of a second risk variant for prostate cancer at $8 q 24$ that is only found in men of African ancestry, these findings strongly reinforce the impo1iance of rarer genetic variation in this region to their greater risk of prostate cancer [25]. Economic instability can cause individuals to resort to cheaper convenient foods that do not provide the vitamins and minerals that are necessary to maintain a healthy lifestyle. Instead, these individuals are resorting to convenient foods that genetically modified, and some of which contain carcinogenic ingredients. These foods are not substantial to our structure.

Prof. Leslie Bourquin (2003) at Michigan State University studied the relationship between diet and tumor development. Dr. Bourquin's studies showed how fruits that contain anthocyanins have the potential to inhibit intestinal tumor development. There are fruits in the Rastafarian diet that contain anthocyanins. These fruits include sea grapes, jamun, and Biggareus cherries [26]. We may not show it much concern; however, it is imperative that we keep a close eye on the foods we consume. Based on The World Health Organization's statistics, America is the ninth obese country in the world [27]. Obesity takes a huge toll on a person's health. It contributes to a long list of serious health problems including diabetes, cardiovascular disease, liver problems, degenerative joint disease, and some types of cancer. What is it that leads us to this severe unhealthy living style? The old saying you are what you eat is one hundred percent true. A fast pace lifestyle results in a selection of food that is convenient. These convenient foods, also known as fast foods; lack nutrients and are genetically modified. These factors have contributed to the high percentages of obesity amongst Americans. However Rastafarian dietary habits are a bit different.

Dietary habits play a very large role in cancer development, along with unawareness as another leading cause of cancer prevalence in the African American community. With these factors being understood as the various causes of cancer, 
what lifestyle change can lessen the probability of cancer development? It is obvious that dietary habits are correlated with cancer development. Therefore, eating healthier is essential to decrease the risk of cancer development. Applying these dietary alterations is just one part of the battle to reducing cancer development probability.

Developing a habit of exercising three to four times a week could have tremendous effects on our health and cancer development probability. Developing a routine will make exercise apart of one's lifestyle. This lifestyle can have tremendous effects on our health and cancer probability. Early detection of cancer can enable treatment to save the patient from experiencing the fatal stages of cancer development. Once cancer has spread throughout the body, the probability of survival is far less. Therefore, regular checkup with a physician is necessary to ensure awareness of any infection.

So, how big of an impact does meditation have on the human body? Can meditation relieve stress and create a healthier lifestyle? Could meditation serve as a therapeutic exercise to help lower the risk of cancer development? Research has shown that it can improve your mood, improve your ability to concentrate, reduce severe depression and anxiety, and boost the immune system. But there is no evidence to suggest that meditation can help to prevent, treat or cure your cancer or any other disease." Meditation also had positive effects on cancer patients that undergo chemotherapy. However, there was no evidence that meditation can prevent cancer development. Mayo Clinic reported "Meditation can give you a sense of calm, peace and balance that benefits both your emotional well-being and your overall health These benefits do not end when your meditation session ends. Meditation can help carry you more calmly through your day and may improve certain medical conditions" [28].

How big of an impact does yoga have on the body? Could yoga serve as an alternate route to lowering risk of cancer development? Yoga is a broad category, considering that there are so many different types of yoga. The article read, "The purpose of yoga is to create strength, awareness and harmony in both the mind and body, explains Natalie Nevins, DO, a board certified osteopathic family physician and certified Kundalini Yoga instructor in Hollywood, California. While there are more than 100 different types, or schools, of yoga, most sessions are typically including breathing exercises, meditation, and assuming postures (sometimes called asana or poses) that stretch and flex various muscle groups.

Yoga is a great tool for staying healthy because it is based on similar principles. The relaxation techniques incorporated in yoga can lessen chronic pain, such as lower back pain, arthritis, headaches and carpal tunnel syndrome," explains Dr. Nevins. "Yoga can also lower blood pressure and reduce insomnia. Other physical benefits of yoga include increased flexibility, increased muscle strength and tone, improved respiration, energy and vitality, maintaining a balanced metabolism, weight reduction, cardio and circulatory health, improved athletic performance and protection from injury".

Metabolomics currently involves a variety of challenges.
Metabolomics requires the development of sophisticated and powerful statistical methodologies to make clinical observations easy to follow [29]. Due to our research, there are obviously many factors that play a role in the prevalence of cancer within African Americans. Considering all the factors that come in to play, the statistics make sense. Change is necessary to lower the risk of cancer development. Change in dietary habits, change in physical activity, change in stress management, and change within ourselves. We must be willing to commit our lives to living a healthy and active lifestyle. If we continue to live the same way, we can't expect to see better results. We learned from this research that we must make a change together, or else these trends will continue to thrive within the African American community [30, 31]. Vitamin D is an essential regulatory hormone for normal human physiology and African American men are disproportionately affected by vitamin D deficiency [32]. Studies demonstrated that the active form of vitamin D, 1, 25-dihydroxyvitamin $\mathrm{D}$, has anti-inflammatory effects by mediating immune-related gene expression in prostate tissue [33]. Studies on demographic, lifestyle, and genetic determinants of circulating concentrations of 25-hydroxyvitamin D [25(OH)D] and vitamin D-binding protein (VDBP) in African American and European American women suggested that African American women have lower concentrations of total 25(OH)D than European American women do, but both groups have similar VDBP concentrations. The study suggested that there are lower concentrations of free 25(OH) D in African Americans [34]. Prostate cancer incidence and mortality rates vary widely among populations, with the highest documented rates among American and Caribbean men of African descent [35]. Therefore, "racespecific" prostate-specific antigen (PSA) needs evaluation in men at high risk for prostate cancer for optimizing early detection [36, 37].

\section{Conclusion}

Although significant progress has already been made, yet this publication is intended to provide information to cancer control advocates, community leaders, public health and health care workers, and other interested in cancer prevention, early detection, and treatment for African Americans. Effective programs must incorporate community participation, innovative outreach, use of social networks and trusted social institutions. Programs that include these strategies are much more likely to be effective in reducing cancer incidence. At Edward Waters College, through the One Florida Cancer Control Alliance's "Minority Education Program", we are determined to increase awareness of prevention, early detection and treatment tools (tobacco control efforts, screening for breast and colorectal cancer, and the dissemination of state-of-the-anti cancer therapies) that can help everyone in our community to lead healthier lives.

Based on our research, we have found that there are multiple factors that can contribute to the high incidence of cancer within the African American community. These factors range from physical activity, socio-economic status, and unawareness about nutrition, diet, tobacco use, overweight, obesity etc. In order to make change within the African American 
community we have to educate our people about the trends that have been in place for years to come. We have to explain why lifestyle changes must be brought about to see a change within the community. Cancer is the second leading cause of death in the United States accounting for twenty two percent of all deaths in this country. Despite all advancements being made in the name of research for cancer and its formalities, African Americans seem to suffer disproportionately among some of the most common types of cancers known. Although several genes and cancers have been studied, only one or two studies per gene for each cancer site have been published, with the exception of breast (CYP1A1 and CYP1Bl), lung (GSTM1, CYP1A1, and NQOl), and prostate (CYP3A4, A293G and CYP17). Economic inequalities which continue to exist among racial groups, in the areas of work, income, education, housing and overall standard of living play a distinct a role in determining the risk factors. Studies have shown that barriers to high-quality health care and racial discrimination are also some determining risk factors. This increases the risk of getting a disease and ultimately dying from the diseases which causes an increase in mortality. All in an attempt to give better insight to increase awareness of prevention, early detection and provide treatment tools that can help lead to overall healthier state of living. As well as produce quality research, determining whether issues regarding the most common forms of cancer among African Americans should be a part of the nation's cancer disparities research agenda. In order for there to be any major changes we must first acknowledge the evidence of disparities in African American culture; bringing awareness to all issues concerning eliminating disparities and the burdens associated with it. It is unlikely that eliminating cancer and other health disparities can be achieved through health care mandate alone, but assessment of the impact of economic, education, and social policies on health outcomes will broaden the agenda toward solutions to eliminate cancer disparities.

\section{References}

1. Ward E, Halpern M, Schrag N, et al. Association of insurance with cancer care utilization and outcomes. CA Cancer J Clin, 2008;58(1): 9-31. doi: 10.3322/CA.2007.0011

2. Bach PB, Schrag D, Brawley OW, Galaznik A, Yakren S, Begg CB. Survival of blacks and whites after a cancer diagnosis.JAMA. 2002;287(16):21062113.

3. Shavers VL, Brown ML. Racial and ethnic disparities in the receipt of cancer treatment. J Natl Cancer Inst. 2002;94(5): 334-357.

4. Smedley BD, Stith AY, Nelson AR, eds. Unequal treatment: confronting racial and ethnic disparities in health care. Committee on Understanding and Eliminating Racial and Ethnic Disparities in Health Care. Washington, DC: National Academy Press;2002.

5. Jemal A, Clegg LX, Ward E, et al. Annual report to the nation on the status of cancer, 1975-2001, with a special feature regarding survival. Cancer. 2004;101(1):3-27. doi: 10.1002/cncr.20288

6. Komenaka IK, Martinez ME, Pennington RE Jr, Hsu CH, Clare SE, Thompson PA, et al. Race and ethnicity and breast cancer outcomes in an underinsured population. J Natl Cancer Inst. 2010;102(15):11781187. doi: $10.1093 /$ jnci/djq215

7. Carey LA, Perou CM, Livasy CA, Dressler LG, Cowan D, Conway K, et al. Race, breast cancer subtypes, and survival in the Carolina Breast Cancer Study. JAMA. 2006;295(21):2492-2502. doi: 10.1001/ jama.295.21.2492

8. Li CI, Malone KE, Darling JR. Differences in breast cancer hormone receptor status and histology by race and ethnicity among women 50 years of age and older. Cancer Epidemiol Biomarkers Prev. 2002;11(7):601-607.

9. Chlebowski RT, Chen Z, Anderson GL, Rohan T, Aragaki A, Lane D, et al. Ethnicity and breast cancer: factors influencing differences in incidence and outcome. J Natl Cancer Inst. 2005;97(6):439-448. doi: 10.1093/jnci/dji064

10. Jemal A, Simard EP, Dorell C, Noone AM, Markowitz LE, Kohler B, et al. Annual Report to the Nation on the Status of Cancer, 1975-2009, Featuring the Burden and Trends in Human Papillomavirus (HPV)Associated Cancers and HPV Vaccination Coverage Levels. JNatl Cancer Inst. 2013. doi: 10.1093/jnci/djs491

11. Wolin KY, Yan Y, Colditz GA. Physical activity and risk of colon adenoma: a meta-analysis. Br J Cancer. 2011;104(5): 882-885. doi: 10.1038/sj.bjc.6606045

12. John Hopkin Medicine. "Specific to African American Population". 2015.

13. John Hopkins Medicine."The Genetics of Pancreatic Cancer". 2009.

14. Batai K, Shah E, Murphy AB, Newsome J, Ruden M, Ahaghotu C. Finemapping of IL-16 gene and prostate cancer risk in African Americans. Cancer Epidemiol Biomarkers Prev. 2012; 21(11): 2059-2068. doi:10.1158/1055-9965.EPI-12-0707

15. Weisburger JH. Nutritional approach to cancer prevention with emphasis on vitamins, antioxidants, and carotenoids. Am J Clin Nutr.1991;53(1): 226S- 237S

16. Young-JoonSurh Y-J. Transcription Factors in the Cellular Signaling Network as Prime Targets of Chemopreventive Phytochemicals. Cancer Ress Ass. 2004; 36(5), 275-286. doi: 10.4143/crt.2004.36.5.275

17. Karen McVeigh on theguardian.com; Karen McVeigh; The Guardian, Wednesday l July 2009

18.http://zipatlas.com/us/fl/jacksonville/zip-code-comparison/ percentage-black-population.htm

19. Waite B, Ph.D., The Common Thread Alliance Tracy L. Johns, Ph.D., University of Florida David Dinkins, University of Florida. An Examination ofN011heast Florida Food Desert Areas: Geographic \&Demographic Descriptors, SNAP Expenditures, \& Purchasing Behaviors

20.http://www.detroitnews.com/story/news/local/michigan/2015/09/ 16/census-us-uninsureddrops-income-stagnates/32499231/ Detroit News I0:42 a.m. EDT September 17, 2015 


\section{1. http://www.cdc.gov/cancer/dcpc/data/ethnic.htm}

22. Friedenreich CM. Physical Activity and Cancer Prevention: From Observational to Interventional Research. Cancer Epidemiol Biomarkers Prev. 2001;10 (4): 287- 301.

23. August KJ, Sorkin DH. Racial/ethnic disparities in exercise and dietary behaviors of middle aged and older adults. J Genet Intern Med. 2011;26 (3):245-250. doi: 10.1007/s11606-010-1514-7

24. Bhardwaj A, Srivastava SK, Khan MA, Prajapati VK, Singh S, Carter JE, et al. Racial disparities in prostate cancer: a molecular perspective. Front Biosci (Landmark Ed). 2017;22:772-782.

25. Han Y, Rand KA, Hazelett DJ, Ingles SA, Kittles RA, Strom SS, et al. Prostate Cancer Susceptibility in Men of African Ancestry at 8q24. J Natl Cancer Inst. 2016;108(7): djv43l. doi: 10.1093/jnci/djv431

26. Kang SY, Seeram NP, Nair MG, Bourquin LD. Tart cherry anthocyanins inhibit tumor development in Apc(Min)mice and reduce proliferation of human colon cancer cells. Cancer Letters. 2003;194:13-19.

27. http://www.who.int/en

28. Meditation: An introduction. National Center for Complementary and Alternative Medicine. http://nccam.nih.gov/health/meditation/ overview.htmAccessed Jan. 27, 2014.

29. Verma M, Bane1jee HR. Metabolomic Approaches in Cancer Epidemiology. Diseases. 2015; 3:167-175. doi:10.3390/ diseases3030167

30. Mandal A, Islam NK, Scott J, Okafor B, Mandal PK. African Americans and Cancer: A Minority Health Advocacy. J Bioprocess Biotech. 2014; doi: $10.4172 / 2155-9821.1000 \mathrm{e} 117$
31. Mandal A, Leger R, Graham L, Ishirnwe N, Vitale A, Innocent $\mathrm{N}$, et al. An Overview of Human Genetic Disorders with Special Reference to African Americans. J Bioprocess Biotech. 2015;5:10. doi:10.4172/2155-9821.1000el39

32. Richards Z, Batai K, Farhat R, Shah E, Makowski A, Gann PH, et al. Prostatic compensation of the vitamin D axis in African American men. JCI Insight. 2017;2(2):e9l 054. doi:10.1172/jci.insight.91054

33. Batai K, Murphy AB, Nonn L, Kittles RA. Vitamin D and Immune Response: Implications for Prostate Cancer in African Americans. Front Immunol. 2016;7:53. doi:10.3389/firnmu.2016.00053

34. Yao S, Hong CC, Bandera EV, Zhu Q Liu S, Cheng TD, et al. Demographic, lifestyle, and genetic determinants of circulating concentrations of 25hydroxyvitarnin D and vitamin 0-binding protein in African American and European American women. Arn J ClinNutr. 2017. doi: 10.3945/ ajcn.116.143248

35. Bock CH, Powell I, Kittles RA, Hsing AW, Carpten J. Racial Disparities in Prostate Cancer Incidence, Biochemical Recurrence, Motiality. Prostate Cancer. 2011; doi:10. 1 155/2011/716178

36. Giri VN, Egleston B, Ruth K, Uzzo RG, Chen DYT, Buyyounouski M, et al. Race, Genetic West African Ancestry, and Prostate Cancer Prediction by Prostate-Specific Antigen in Prospectively Screened High Risk Men. Cancer Prev Res. 2009; 2(3). doi:10.1158/1940-6207

37. Major JM, Oliver MN, Doubeni CA, Hollenbeck AR, Graubard BI, Sinha R. Socioeconomic status, health care density, and risk of prostate cancer among African-American and Caucasian men in a large prospective study. Cancer Causes Control. 2012;23(7):1185-1191. doi: 10.1007/ s10552-012-9988-8 